\title{
Neuropsychological Evaluation and Rehabilitation after Acquired Brain Injury
}

\author{
Paula Adriana Rodrigues de Gouveia ${ }^{1}$ \\ Shirley Silva Lacerda \\ Ana Merzel Kernkraut \\ Israelita Albert Einstein Hospital, São Paulo, SP, Brazil
}

\begin{abstract}
Symptoms of interhemispheric disconnection after acquired brain injury are unusual in the current clinical practice. Symptoms usually diminish spontaneously and may include tactile anomia, agraphia and left signs of competition between the hemispheres, such as "alien hand sign". This work presents a case report of a 33 year old patient who developed symptoms of interhemispheric disconnection and executive function deficits after surgery for removal of a tumor in the pituitary region, as well as the evaluation of the applicability of the neuropsychological rehabilitation program for the cognitive complaints presented. The patient was evaluated with standardized neuropsychological instruments before starting rehabilitation and again close to the discharge from treatment. The case study was conducted by analyzing intervention data and the clinical outcome of the patient in the institutional records (results of neuropsychological evaluation examination and records of interventions in rehabilitation sessions). Throughout his evolution, the patient showed improvement in cognitive symptoms and demonstrated benefits from the training and strategies used for his adaptation and return to work and other previous activities. The study highlights the importance of conducting more studies of neuropsychological interventions for individuals with cognitive deficits.
\end{abstract}

Keywords: Cognition, rehabilitation, injury, apraxia, frontal lobe.

\section{Avaliação e Reabilitação Neuropsicológica após Lesão Encefálica Adquirida}

\section{Resumo}

Sintomas de desconexão inter-hemisférica após lesão cerebral adquirida são pouco usuais na prática clínica atualmente. Os sintomas costumam diminuir espontaneamente e podem incluir anomia táctil, agrafia à esquerda e sinais de competição entre os hemisférios, como o "sinal da mão alienígena". Este trabalho tem por objetivo apresentar um relato de caso clínico de paciente de 33 anos, que evoluiu com sintomas de desconexão inter-hemisférica e alterações de funções executivas, após intervenção cirúrgica para remoção de tumor em região da hipófise, além de avaliar a aplicabilidade de programa de reabilitação neuropsicológica para as queixas cognitivas apresentadas. O paciente foi avaliado com instrumentos neuropsicológicos padronizados antes de iniciar a reabilitação e próximo à alta do tratamento. $\mathrm{O}$ estudo

1 Mailing address: Israelita Albert Einstein Hospital, Centro de Reabilitação, Av. Albert Einstein, 627, São Paulo, SP, Brazil 05652-900. E-mail: paularg@einstein.br

Acknowledgments: Dr. Cicero José Nunes Vaz (Physiatrist Doctor) and the other professionals of the Rehabilitation Center who accompanied patient D. T. (the Physiotherapy, Occupational Therapy and Speech Therapy teams), with whom we had the opportunity to discuss the case and exchange valuable impressions for the planning of the work and integration of the care for the patient. 
de caso foi realizado a partir da análise de dados de intervenção e evolução clínica do paciente em prontuário institucional (resultados de exame de avaliação neuropsicológica e registros de intervenções em sessões de reabilitação). Ao longo de sua evolução, o paciente apresentou melhora dos sintomas cognitivos e demonstrou benefício com os treinos e estratégias utilizados para sua adaptação, bem como para retomar o trabalho e outras atividades prévias. Destaca-se ainda a importância de se realizar mais estudos de intervenções neuropsicológicas para indivíduos com déficits cognitivos.

Palavras-chave: Cognição, reabilitação, lesão, apraxia, lobo frontal.

\section{Evaluación y Rehabilitación Neuropsicológica después de una Lesión Cerebral Adquirida}

\section{Resumen}

Los síntomas de desconexión interhemisférica después de una lesión cerebral adquirida son inusuales en la práctica clínica actual. Los síntomas generalmente disminuyen de forma espontánea y pueden incluir anomia táctil, agrafía izquierda y signos de la competencia entre los hemisférios. Este estudio tiene como objetivo presentar un caso clínico de un paciente de 33 años, que desarrollaron síntomas de desconexión interhemisférica después de la cirugía para la extirpación del tumor en la región pituitaria y alteraciones en la función ejecutiva y evaluar la aplicabilidad del programa de rehabilitación neuropsicológica para las quejas cognitivas. El paciente fue evaluado con instrumentos neuropsicológicas estandarizadas antes de comenzar la rehabilitación y cerca del máximo tratamiento. El estudio de caso se llevó a cabo a partir del análisis de datos de intervención y el desarrollo clínico del paciente registro médico institucional (resultados de los exámenes de evaluación neuropsicológica y las intervenciones en los registros de las sesiones de rehabilitación). A lo largo de su evolución, el paciente mostró una mejoría en los síntomas cognitivos y demostró un beneficio con la formación y las estrategias utilizadas para adaptarse y para reanudar el trabajo y otras actividades anteriores. También pone de relieve la importancia de llevar a cabo más estudios de intervenciones neuropsicológicas para las personas con déficits cognitivos.

Palabras clave: La cognición, la rehabilitación, lesiones, apraxia, lóbulo frontal.

Patients with injuries in the connections between the hemispheres may have symptoms characteristic of interhemispheric disconnection syndrome (Geschwind, 1965a; Gil, 2002; Loring, 1999; Sperry, Gazzaniga, \& Bogen, 1969). Knowledge of the neuropsychological symptoms resulting from the disconnection of the hemispheres was derived from the study of patients who underwent resection of the corpus callosum in the treatment of refractory epilepsy.

Interhemispheric disconnection syndrome, as described by Sperry et al. (1969), is characterized by symptoms such as visual and tactile anomie, absence of interhemispheric transference of unilateral somatosensory stimulation of both hands, hemialexia and unilateral left-side apraxia. The signs of callus disconnection are not usually very obvious and can spontaneously decrease some time after the lesion. They can also be compensated for by the patients, especially if the commissurotomy is only partial, affecting only some sensory modalities. They only become clear in specific conditions of the examination, in which access to information from the other hemisphere may be controlled (Browndyke, 2002; Rubens, Geschwind, Mahowald, \& Mastri, 1977). Symptoms such as left-sided tactile anomia (the subject is unable to name objects in the left hand with eyes closed, because the tactile information does not reach the left hemisphere to be named), left agraphia (inability to produce legible writing due to prejudice in the transfer of kinesthetic visual information between the hemispheres) and signs of conflict or competition between members or "signs of alien hand syndrome" (the patient has no control of 
actions carried out by one hand or presents clear competition in which one hand undoes what the other just did), are some examples of clinical manifestations of this condition (Browndyke, 2002; Geschwind, 1965b).

The neuropsychological evaluation allows the examination of several cognitive spheres, through specific instruments for each skill assessed, allowing the observation of symptoms associated with the interhemispheric disconnection condition. The impact of these and other symptoms associated with brain injury may interfere with the autonomy of the patient and his/her complete return to previous activities. Deficits in executive functions are examples of symptoms with significant impact on the autonomy of affected individuals, due to their impact on the organization, planning and monitoring of behavior and intentional actions (Levine et al., 2011).

Neuropsychological rehabilitation treatment aims to minimize the cognitive deficits, so that the patients achieve their best level of functionality in daily life (Wilson, 2008). The work is performed through guidance regarding cognitive functioning, training to improve the skills affected and the use of compensatory strategies. Interventions directed toward difficulties in executive functions include anticipation and planning of actions, decomposition of plans into steps or "step by step" and checklists of tasks, as ways to organize and monitor the behavior (Sohlberg, 2009; von Cramon, Matthes-von Cramon, \& Mai, 1991).

Traditionally, in the area of Neuropsychology there have been many studies of the evaluation of cognitive functions, due to efforts to amplify the comprehension of cognitive functioning, both in healthy people and in individuals who have suffered some kind of cerebral alteration or dysfunction. Quantitative data obtained from standardized instruments, facilitate the comparison between tests and groups of individuals. However, neuropsychological rehabilitation studies present a greater methodological challenge, especially due to the frequent need to individualize strategies focused on functional deficits rather than only on training of a specific function. This is because the main goal of the treatment is to gain autonomy in daily activities (Battistella \& Brito, 2002; World Health Organization [WHO], 1980), which can often only be achieved through adaptations and compensations for difficulties. Therefore, case studies in neuropsychological rehabilitation of acquired injuries are a major source of descriptions and practical models of work with patients and their families, as they provide information about the clinical context and common obstacles in the daily lives of those who deal with these cases (Bolognani, Gouveia, Brucki, \& Bueno, 2000; Fish, Manly, \& Wilson, 2008; Fleming, Shum, Strong, \& Lightbody, 2005; Gouveia, Brucki, Bolognani, Bezerra, \& Bueno, 2000; Gouveia, Prade, Lacerda, Boschetti, \& Andreoli, 2009; Wall, Turner, \& Clarke, 2013).

The aim of this study is to present a case report of unusual symptoms of interhemispheric disconnection, accompanied by deficits in executive function after acquired brain injury. Neuropsychological rehabilitation strategies are also presented and their applicability in this case is evaluated. This study was approved by the Research Ethics Committee of the Israelita Albert Einstein Hospital (CAAE: 26623814.8.0000.0071).

\section{Case Report}

The patient, D.T., male, 33 years of age, left-handed and married (his wife was pregnant with their first child), with a degree in Accounting Sciences and a post-graduate qualification. He worked as a tax manager in a private company. In May 2011 he began to present visual deficits and his ophthalmologist referred him to a neurologist, who diagnosed pituitary adenoma, after examinations. The patient then underwent surgery to remove the tumor. Left fronto-temporal parietal craniotomy was performed and postoperatively the patient developed bacteremia, pulmonary embolism and thrombosis in the left lower limb.

After discharge, he complained of difficulties concentrating on prolonged activities, apathy, difficulty in writing, in typing on the 
computer and in carrying out activities with the left hand. He also showed anxiety, sadness and irritability. The Magnetic Resonance Imaging (MRI) examination of the head performed in June of that year indicated signs of surgical manipulation of the sella turcica with postoperative alterations in the soft tissues, together with the left fronto-temporal parietal craniotomy, deficits in the signal in the corpus callosum, cingulate gyrus, white matter of the frontal lobe and the head of the left caudate nucleus, compatible with an ischemic event in the subacute phase, in the territory of branches of the left anterior cerebral artery.

The patient came to the Rehabilitation Center of the Albert Einstein Hospital and started being accompanied by the physiatrist doctor. $\mathrm{He}$ was referred to multidisciplinary rehabilitation, with physical therapy, occupational therapy, speech therapy and neuropsychology sessions.

\section{Neuropsychological Evaluation}

The first evaluation, performed two months after the surgery, indicated discrete difficulties regarding the working memory skills, range of verbal learning, verbal fluency and visual functions (identification, synthesis and perceptual organization). Moderate to severe difficulties were also observed in relation to attention/executive functions, motor functions (graphomotor, writing and simultaneous bimanual manipulation), visuospatial skills (simple and complex constructive praxis) and information processing speed (Table 1).

The patient also presented deficits associated with frontal dysfunctions and hemispheric disconnection syndrome. Thus, in graphomotor activities involving writing and production of drawings, he exhibited serious difficulties with respect to the writing, with evident competition between hands when using the pencil. The same competitive behavior between the hands was observed whenever he was asked to manipulate objects and perform activities that required simultaneous use of the hands. In design construction activities with cubes, for example, several times the right hand (aided by language) put the pieces in the correct position to form the required de- sign, while the left hand removed the piece from the place, putting it in an incorrect position. In another visual-spatial abstraction task, it was the left hand that indicated the correct response, while the right hand indicated the incorrect response, consistent with the equally mistaken verbal response (left hemisphere).

In the tactile agnosia evaluation task, the patient presented severe difficulties in recognizing and naming objects without visual support, using the left hand. However, when this same activity was carried out with the possibility of multiple choice responses (with the presence of the objects), the patient was able to readily identify and name each element due to the presence of visual information for both hemispheres.

The results of the neuropsychological assessment of the patient are shown in Table 1 . Due to the high level of education and previous cultural level, in the evaluation his results were compared with standards from a similar population. The patient was reevaluated five months after the first evaluation ( 7 months after the injury) and presented improvements in the majority of the skills examined. In the reevaluation the method of comparison between 2 evaluations proposed by Strauss, Sherman, and Spreen (2006) was used, which calculates the confidence interval of the Reliable Change Index for the scores of the first evaluation. Thus, a confidence interval is assigned for each of the first evaluation score and, if the second evaluation scores are outside this range, it is considered that there was a significant change between the first and second evaluation scores. In this study a $90 \%$ confidence interval was chosen.

\section{Neuropsychological Rehabilitation}

The treatment began six weeks after the neuropsychological evaluation. At the end of the evaluation the patient was advised about the symptoms resulting from hemispheric disconnection that caused strangeness and perplexity to the patient and his family. He did not understand why his hand (especially the left) did not obey him and why his hands were acting independently. After realizing and better understand the manual competition symptoms, 
the patient was instructed to try to perform manual tasks with just one hand. Thus, D.T. put one hand behind his back and performed the activity with the other, when possible, reducing the competition between them. However, with the passing of some days, at the beginning of the formal rehabilitation, these complaints had diminished enough due to the evolution of the neurological condition. Only the difficulty of writing related to this condition continued to affect his daily functioning.

When starting the rehabilitation program the patient was using sertraline, and was again driving. He had decreased manual competition complaints, however, continued to have memory failures regarding appointments, tasks and taking medication and decreased initiative, although he hoped to return to work as quickly as possible. Another relevant complaint, associated with the executive functions, was described as "paralysis" or feeling of "lock" to start a certain action or to decide what to do. For example, he arrived at the bakery and was paralyzed, being unable to decide whether to ask for something to take away or sit for a meal. Also, he was surprised by rain when leaving a place and did not know how to proceed. The patient underwent the treatment twice a week for a period of eight months, with two months of monthly follow up sessions.

The proposed goals were listed, with the patient and his family, giving priority to the complaints of greater functional impact, such as remembering appointments and taking medication. Many of the strategies introduced to remember to perform certain actions were more associated with executive function failures than with memory itself, because the formal assessment indicated preservation of the episodic memory, and this information corroborated complaints of prospective memory and not of recalling events and recent data. The difficulties of writing were addressed in the speech therapy sessions. Initially they included training using block letters and typing on the computer, until the patient could again automate motor planning in the production of writing. Later the patient began to train in the use of cursive writing, which was more difficult for him.
The goals were reviewed considering an event that would change his whole routine and represented a great challenge for the patient: the return to work. It was a delicate situation that occurred a little earlier than planned because the patient was considered fit for work before the period recommended by the physician. In addition to generating anxiety, the return brought the risk of the patient not being able to resume his former position. In this sense, new strategies were created, based on the complaints and observations made by the patient, who felt lost and was unsure about how to organize his tasks.

As the patient was considered fit to return to the work prematurely, there was a possibility of him being unable to perform his work activities and the fear that his employer and work team could perceive some difficulty and that this situation would adversely expose the limitations of the patient, threatening his remaining in the company. In this case, the employer conducted an interview with the patient before his return and showed no concern about the ability of the patient, understanding that he would be recovered.

Initially, a reduction of the working day was negotiated, to be gradually increased, which did not last long, due to the need to perform various tasks and the patient's own desire not to present difficulties, although it left him very tired in the first few weeks. After inclusion of adaptations to the work activities, contact was made with an employee who had worked with him for a long time, since his direct manager had changed. Contact with this colleague served to raise potential problems and failures of the patient on a daily basis, without exposing him through formal contact with the company, questioning his efficiency.

The main interventions during the neuropsychological rehabilitation are described in Figure 1.

At the end of the rehabilitation, which lasted approximately eight months, the patient was working, well adapted to his new routine, and was using the strategies described. There was a significant decrease in the previous complaints 
Goals and

Objectives

Intervention Strategies

Results

Initial goals

Remember to take medicine on time.

Do not miss appointments. in the routine / Improve initiative.

Improve attention.

Reduce episodes of disorganization in everyday situations ("lock").

Improve planning and abstraction.
Increase activities

- Use of alarm on the phone.

- Use of agenda on the phone and of the reminder function with alarm.

- Wife was advised to request more help in routine tasks such as shopping;

- Organization of the routine with fixed activities, such as speech therapy exercises and physical activity;

- Introduction of list of daily activities, with activities selected by the patient and wife.

- Training through pencil and paper and computer exercises: RehaCom (Schuhfried, 2003).

- Use of step by step in situations with greater frequency of occurrences, such as going to the bakery, for example;

- Guidance to generalize the strategy to other situations.

- Planning exercises with hypothetical situations for solution of problems.

- Text exercises for interpretation of meaning and generation of hypotheses.

\section{Goals after} returning to work

Increase perception of the difficulties of executive functions.

Increase initiative and organization for tasks at work.
- Psychoeducation through texts on executive functions and strategies for management of the difficulties;

- Analysis of episodes that occurred with him to illustrate the difficulties.

- List of task at work (To do List); - Step by step for problem solving.
Return to take notes in business meetings.

Check his performance in the workplace.
- Use of Tablet to compensate for written errors that embarrassed him in public.

- Telephone contact with co-worker close to D.T. to know whether he saw cognitive and/or behavioral problems.
Patient began taking the medication at the correct time.

Patient stopped forgetting most of his appointments.

Patient extended number of activities in the routine, such as shopping and helping the wife, as well as speech exercises. Although he was resistant to physical activity, which he ceased to practice regularly.

Reduction of errors and increased response speed in sustained and divided attention, inhibitory control and working memory exercises.

Patient began to plan before leaving home, what he would ask for at the bakery, and mentally rehearse the activity.

In unexpected situations, such as faced with rain when leaving the office without an umbrella, he tried to stop and think about the options. Eventually he would still be "paralyzed" but then would react.

-Decreased response generation time and improved response quality.

-Improved understanding of subtleties and complex content in the exercises.

Patient began to better understand and admit difficulties that he previously minimized. From the episodes it was possible to develop specific strategy for the situation.

- Ceased waiting for someone to ask him to do something.

He started following the list, preventing tasks being delayed.

- Faced with new demands, he began to draw up an action plan so as not to be paralyzed, not knowing how to begin. Eventually he was still insecure and had difficulty organizing himself.

- He resumed taking notes using the electronic resource without embarrassment.

- His colleague did not mention seeing difficulties in carrying out tasks or performing meetings with the team. He just noticed that the patient was quieter than before the neurological condition. 
and the patient was more successful in managing new problems, or unexpected events at home and at work, using the strategies learned. These strategies involving step-by-step instructions and practice of self monitoring to replan his actions whenever he realized he did not know how to act.

His wife still thought that his initiative was somewhat reduced, based on his pre-morbid profile, as was his pro-activity to help in some situations with his young daughter and to make decisions. However, she no longer felt helpless and overwhelmed with the management of the home and family, as she had before. Due to the decrease in the frequency of episodes of "paralysis" and improvements in decision-making, he became more able to take on tasks in the home and care for his daughter, reducing the need to ask and be supervised by his wife.

The comparison between the two evaluations showed significant improvement in performance in various instruments, in the majority of the evaluated skills, such as the skills of: working memory, divided attention, graphomotor (including the remission of manual competition behaviors), verbal and visual memory, constructive praxis, calculation, executive functions and intellectual functioning (verbal and execution spheres). The evaluation of mood also showed a reduction in depressive symptoms, which corroborated the observation during the consultations and the perception of the patient and family. However, the persistence of discrete deficits in executive functions was observed, which manifested in more complex situations involving new situations and decision-making, leading to the patient still needing to use specific strategies, especially at work.

\section{Discussion}

This study presented a case report of evaluation and rehabilitation of a patient with cognitive deficits, involving symptoms of executive dysfunction and interhemispheric disconnection syndrome. The patient developed a rapid remission of the symptoms of disconnection, however, needed strategies to minimize the attention and executive function deficits, achieving satisfactory results in terms of adaptation and return to previous activities. The role of the spontaneous improvement in the recovery of the patient should be highlighted, due to the short time elapsed from the injury to the start of the process, as well as the severity of the injury (mild to moderate; Gouveia, 2006; Kolb, 2004). In this case, combining the recent condition of the injury with cognitive function training showed good results. In general, patients with a severe degree of commitment and/or involvement of various cognitive spheres and longer injury time (chronic condition), often show limited improvement of the actual cognitive functions, measured in the formal neuropsychological evaluation.

Rehabilitation interventions contribute more significantly to the well being of the patient when they prioritize the autonomy and functionality, addressing the complaints present rather than only the cognitive deficits indicated in the formal evaluation (Ben-Yishay, 2000; Gouveia et al., 2009; Trexler, 2000). Many of the strategies used in this case were designed to minimize subtle difficulties in executive functions. Despite the challenge, there is a great advantage in developing strategies personalized to the requirement of the patient, i.e. creating and adapting resources for the type of situation in which the patient feels difficulty. A relevant question that usually occurs in these cases of executive function deficits is that the patient does not always realize his/her limitations and tends to minimize lapses and failures, due to anosognosia (Goldberg, 2002). In this case, the reports of the wife and of a co-worker of the patient helped in identifying some important situations throughout the process.

During the treatment it is necessary to monitor the daily situations in which difficulties manifest themselves, in order to propose something contextualized and at the same time feasible to perform. Furthermore, it is always important to check the effectiveness of the assistance and adapt it if necessary (Wilson, 1999). An example of this was the return to work. New targets were created from this change, to cover impor- 
Table 1

Comparison of Results of the Two Neuropsychological Evaluations

\begin{tabular}{|c|c|c|c|c|c|c|}
\hline & GS 1 & Perc 1 & GS 2 & Perc 2 & $90 \%$ RCI-CI* & Comparison \\
\hline \multicolumn{7}{|l|}{ Attention and Executive Functions } \\
\hline Digits Forward & 6 & 31 & 6 & 31 & 5.06 to 6.94 & ns \\
\hline Digits Backward & 4 & 27 & 4 & 27 & 4.00 to 5.00 & ns \\
\hline Trail Making Test A & 157 & 0.1 & 48 & 4 & 145.95 to 168.05 & $\uparrow$ \\
\hline Trail Making Test B & 431 & 0.1 & 69 & 42 & 413.00 to 449.00 & $\uparrow$ \\
\hline Stroop 1 & 11 & 54 & 9 & 90 & 9.77 to 12.23 & $\uparrow$ \\
\hline Stroop 2 & 11 & 86 & 12 & 76 & 8.46 to 13.54 & ns \\
\hline Stroop 3 & 15 & 86 & 14 & 88 & 8.38 to 21.62 & ns \\
\hline WCST Categories & 1 & 0.6 & 2 & 4 & 0 to 2.83 & ns \\
\hline WSCT Errors & 28 & 2 & 19 & 18 & 18.13 to 37.87 & ns \\
\hline WCST Pers. Response & 8 & 34 & 15 & 1 & 1.62 to 14.38 & $\downarrow$ \\
\hline WCST Pers. Errors & 7 & 34 & 13 & 0.7 & 2.16 to 11.84 & $\downarrow$ \\
\hline WCST Non-pers. Errors & 21 & 0.7 & 6 & 50 & 13.32 to 28.68 & $\uparrow$ \\
\hline WCST Loss of Goal & 1 & 18 & 1 & 18 & 0 to 2.17 & ns \\
\hline \multicolumn{7}{|l|}{ Memory } \\
\hline RAVLT A1 & 4 & 8 & 6 & 42 & 2.75 to 5.25 & $\uparrow$ \\
\hline RAVLT A5 & 12 & 58 & 14 & 84 & 10.17 to 13.83 & $\uparrow$ \\
\hline RAVLT Total & 40 & 21 & 58 & 82 & 32.45 to 47.55 & $\uparrow$ \\
\hline RAVLT A6 & 7 & 21 & 11 & 66 & 4.58 to 9.42 & $\uparrow$ \\
\hline RAVLT A7 & 7 & 18 & 10 & 50 & 7.17 to 10.83 & $\uparrow$ \\
\hline Logical Memory I (WMS-R) & 29 & 62 & 34 & 90 & 19.83 to 38.17 & ns \\
\hline Logical Memory II (WMS-R) & 20 & 41 & 29 & 80 & 10.06 to 29.94 & ns \\
\hline Visual Reproduction I (WMS-R) & 18 & 2 & 38 & 90 & 10.67 to 25.33 & $\uparrow$ \\
\hline Visual Reproduction II (WMS-R) & 6 & 1 & 40 & 99 & 0.00 to 14.43 & $\uparrow$ \\
\hline \multicolumn{7}{|l|}{ Language } \\
\hline Phonemic Verbal Fluency & 41 & 38 & 46 & 54 & 30.29 to 51.71 & ns \\
\hline Semantic Verbal Fluency & 16 & 14 & 28 & 86 & 10.84 to 21.16 & $\uparrow$ \\
\hline Boston Naming Test & 56 & 54 & 57 & 62 & 53.36 to 58.64 & ns \\
\hline \multicolumn{7}{|l|}{ Visuospatial Skills } \\
\hline Clock Drawing Test & 12 & 0.1 & 13 & 0.3 & 11.35 to 12.65 & $\uparrow$ \\
\hline Hooper V O T & 29 & 76 & 30 & 82 & 26.07 to 30.00 & ns \\
\hline Rey CFT- Copy & 24 & 0.3 & 33 & 54 & 19.32 to 28.68 & $\uparrow$ \\
\hline \multirow[t]{2}{*}{ Rey CFT - Memory } & 22 & 69 & 29 & 95 & 15.11 to 28.89 & $\uparrow$ \\
\hline & IDD 2 & Perc. 1 & IDD 2 & Perc. 2 & RCI-90\% CI* & Comparison \\
\hline \multicolumn{7}{|l|}{ Intellectual Functions } \\
\hline WAIS-III - Vocabulary & 10 & 50 & 9 & 37 & 8.30 to 11.70 & ns \\
\hline WAIS-III - Similarities & 9 & 37 & 11 & 63 & 6.83 to 11.17 & ns \\
\hline
\end{tabular}




\begin{tabular}{lcccccc} 
WAIS-III - Arithmetic & 9 & 37 & 11 & 63 & 6.32 to 11.68 & ns \\
WAIS-III - Digit Span & 7 & 16 & 8 & 25 & 4.42 to 9.58 & $\mathrm{~ns}$ \\
WAIS-III - Information & 10 & 50 & 12 & 75 & 8.41 to 11.59 & $\uparrow$ \\
WAIS-III - -Letter- Num Seq. & 5 & 5 & 9 & 37 & 1.85 to 8.15 & $\uparrow$ \\
WAIS-III - Picture Comp & 6 & 9 & 9 & 37 & 2.81 to 9.19 & $\mathrm{~ns}$ \\
WAIS-III - Digit Symbol & 2 & 0.4 & 9 & 2 & 0 to 4.69 & $\mathrm{~ns}$ \\
WAIS-III - Block Design & 6 & 9 & 9 & 37 & 3.83 to 8.17 & $\uparrow$ \\
WAIS-III - Matrix Rea. & 9 & 37 & 11 & 63 & 5.98 to 12.02 & ns \\
WAIS-III - Sym. Search & 4 & 2 & 9 & 37 & 1.15 to 6.85 & $\uparrow$ \\
\hline & IQ 1 & Perc. 1 & IQ 2 & Perc. 2 & $90 \%$ RCI-CI* & Comparison \\
\hline Indices of IQ & & & & & & \\
WAIS-III - Verbal IQ & 93 & 32 & 102 & 55 & 86.32 to 99.68 & $\uparrow$ \\
WAIS-III - Performance IQ & 74 & 4 & 87 & 19 & 63.88 to 84.12 & $\uparrow$ \\
WAIS-III - Full-Scale IQ & 84 & 14 & 96 & 39 & 77.37 to 90.63 & $\uparrow$ \\
WAIS-III - Verbal Comp. & 98 & 45 & 103 & 58 & 90.69 to 105.31 & ns \\
WAIS-III - Perceptual Org. & 82 & 12 & 97 & 42 & 70.51 to 93.49 & $\uparrow$ \\
WAIS-III - Working Memory & 82 & 12 & 95 & 37 & 70.85 to 93.15 & $\uparrow$ \\
WAIS-III - Processing speed & 66 & 1 & 81 & 10 & 54.67 to 77.33 & $\uparrow$ \\
\hline
\end{tabular}

Notes. Legend: $\mathrm{ns}=$ Performance change not significant; $\uparrow=$ Significant improvement in performance; $\downarrow=$ Significant worsening of performance; GS1= Gross score of the first assessment; GS2= Gross score of the second evaluation; Perc. 1= Percentile of the first evaluation; Perc. 2 = Percentile of the second evaluation; Trail making test A and B (Campanholo et al., 2014; Reitan, 1958); Stroop = Stroop Color-Word Test (Campanholo et al., 2014; Strauss et al., 2006); WCST = Wisconsin Card Sorting Test (Heaton, Chelune Talley, Kay, \& Curtiss, 1993); WCST Pers./Non-pers. = WCST Perservative/Non- perservative; RAVLT = Rey Auditory Verbal Learning Test (Lacerda, Andreoli, Andreoli \& 2008; Schmidt, 1996); WMS-R = Wechsler Memory Scale Revised (Martins, Bolognani, Pompeia, Bueno, \& Miranda, 2015; Wechsler, 1987); Hooper VOT = Hooper Visual Organization Test (Strauss et al., 2006; Tosello, 2005); Rey CFT = Rey Complex Figure Test (Osterrieth, 1944; Strauss et al., 2006); WAIS-III = Wechsler Adult Intelligence Scale Third Edition (Wechsler, 2004); Letter-Num Seq. = Letter-Number Sequencing; Picture Comp = Picture Completion; Matrix Rea. = Matrix Reasoning; Digit Symbol = Digit Symbol Coding; IQ= Intellectual Quotient; Verbal Comp. = Verbal Comprehension; Perceptual Org. = Perceptual Organization. *RCI-CI= Reliable Change Index Confidence Interval: RCI-CI $=\mathrm{EB} 1 \pm\left(z .\left(\sqrt{ } 2 .(S D \cdot \sqrt{ } 1-\alpha)^{2}\right)\right.$, where $z$ is confidence interval value, $S D$ is the standard deviation of the sample of standardization and $\alpha$ is the test-retest reliability value (Strauss et al., 2006).

tant situations involving cognitive demands that were not previously present. The return to work is a very delicate stage and not always possible for patients with severe limitations, who require significant changes in their work demands, in terms of the amount of work, time for its execution, complexity and responsibility involved in the type of task. In this case, a change of area or workplace can be negotiated, where this possibility exists. Patients who work in family businesses or have greater flexibility of time and environment to perform their tasks in general can return more easily, with less pressure, especially due to the fact that they can change activity more easily.

Whenever the return to work is considered, it is necessary to study what activities and functions can be performed, to make a survey of the cognitive demands involved and the environmental factors that may favor or hinder the performance of the patient. An example would be an environment with distracters, such as many people and lots of noise. As these patients usually present attentional and organizational supervisory difficulties, they benefit from closed environments and a routine of structured activi- 
ties. The survey of this information allows an analysis of each step, so that specific training can be developed and adaptations implemented to minimize unfavorable conditions. In the daily practice, we often observe that the general public is not aware of the type of cognitive or behavioral deficits individuals with acquired brain injury may present. On one hand, this could decrease the stigma of the patient trying to resume his/ her professional activities after a brain injury, on the other, it can hinder the acceptance and understanding of the need to propose adaptations and modifications in the workplace. When the individual demonstrates some difficulty, rather than this being seen as something specific, related to a skill, there is a lot of confusion on the part of colleagues and managers, who attribute the difficulties to mood, motivation and engagement problems, which ends up affecting the relationship of the patient in the workplace. Given this scenario, it is necessary to guide the people directly related with the patient regarding the changes, the reason for their different behavior and their current difficulties, aiming to increasing tolerance and acceptance of the adjustments required for the patient to return to the routine of the sector. Thus, the return to work is an ambitious goal during the rehabilitation process, which should be evaluated with caution, since it is necessary to prevent the individual being put in an unfavorable situation, exposing his/her limitations, while he/she needs understanding and support in the workplace, to make use of adjustments and adapt to the demands of the work (Bjorkdahl, 2010; Hofgren, Esbjornsson, \& Sunnerhagen, 2010; Hooson, Coetzer, Stew, \& Moore, 2013).

It should be noted that the current study had some important limitations, such as the role of spontaneous recovery during the rehabilitation treatment, since the patient was still in a recent recovery phase from the acquired injury. Another point to be considered was the absence of specific interventions for the symptoms of hemispheric disconnection, which spontaneously remitted almost totally, especially due to the patient taking a few weeks to start the neuropsychological rehabilitation sessions, after finalizing the evaluation of the cognitive functions.
Meta-analysis studies on neuropsychological rehabilitation criticize the low number of prospective, controlled and randomized studies in this area (Cicerone et al., 2011), which makes consensus on the best intervention practices difficult, especially regarding the training of cognitive functions. On the other hand, some studies suggest that the use of compensatory strategies and training personalized for the difficulties of patients, allows the goals to be evaluated according to the gains in functionality and autonomy they provide, resulting in good evidence (BaharFuchs, Clare, \& Woods, 2013). When we consider the use of compensatory strategies, case reports represent an important source of information, as they exemplify the forms of inclusion of assistance in the routine of the patient and describe ways of dealing with the individual failures and adjustments of the resources used. We hope this study has clearly presented the goals and the steps of the rehabilitation work, in the management of the cognitive difficulties described here. Future studies could address the specific issue of the return to work, as there are few studies in the literature that present the inclusion of these patients in productive activities, whether seeking a new job or trying to regain their previous position.

\section{References}

Bahar-Fuchs, A., Clare, L., \& Woods, B. (2013). Cognitive training and cognitive rehabilitation for persons with mild to moderate dementia of the Alzheimer's or vascular type: A review. Alzheimer's Research \& Therapy, 5(4), 35. doi:10.1186/alzrt189

Battistella, L. R., \& Brito, C. M. M. (2002). Classificação internacional da funcionalidade. Acta Fisiátrica, 9, 98-101.

Ben-Yishay, Y. (2000). Neuropsychological rehabilitation: A holistic perspective. In A.-L. Christensen \& B. P. Uzzell (Eds.), International Handbook of Neuropsychological Rehabilitation. New York: Kluwer Academic.

Bjorkdahl, A. (2010). The return to work after a neuropsychological programme and prognostic factors for success. Brain Injury, 24(9), 1061-1069. doi:10.3109/02699052.2010.494588 
Bolognani, S. A., Gouveia, P. A., Brucki, S. M., \& Bueno, O. F. (2000). [Implicit memory and its contribution to the rehabilitation of an amnesic patient: Case report]. Arquivos de NeuroPsiquiatria, 58(3B), 924-930.

Browndyke, J. N. (2002). Callosal disconnexion syndromes. Neuropsychology Central. Retrieved from http://www.neuropsychologycentral.com/

Campanholo, K. R., Romão, M. A., Machado, M. A. R., Serrao, V. T., Coutinho, D. G. C., Benute, G. R. G., ...Lucia, M. C. S. (2014). Performance of an adult Brazilian sample on the Trail Making Test and Stroop Test. Dementia e Neuropsychologia, 8(1), 26-31.

Cicerone, K. D., Langenbahn, D. M., Braden, C., Malec, J. F., Kalmar, K., Fraas, M., ...Ashman, T. (2011). Evidence-based cognitive rehabilitation: Updated review of the literature from 2003 through 2008. Archives of Physical Medicine and Rehabilitation, 92(4), 519-530. doi:10.1016/j.apmr.2010.11.015

Fish, J., Manly, T., \& Wilson, B. A. (2008). Longterm compensatory treatment of organizational deficits in a patient with bilateral frontal lobe damage. Journal of the International Neuropsychological Society, 14(1), 154-163. doi:10.1017/ S1355617708080120

Fleming, J. M., Shum, D., Strong, J., \& Lightbody, S. (2005). Prospective memory rehabilitation for adults with traumatic brain injury: A compensatory training programme. Brain Injury, 19(1), $1-10$.

Geschwind, N. (1965a). Disconnexion syndromes in animals and man. I. Brain, 88(2), 237-294.

Geschwind, N. (1965b). Disconnexion syndromes in animals and man. II. Brain, 88(3), 585-644.

Gil, R. (2002). Neuropsicologia. São Paulo, SP: Santos.

Goldberg, E. (2002). O cérebro executivo: Lobos frontais e a mente civilizada. Rio de Janeiro, RJ: Imago.

Gouveia, P. A., Brucki, S. M., Bolognani, S. A., Bezerra, A. B., \& Bueno, O. F. (2000). [Procedures to improve daily activities performance in individuals with cerebral anoxia: Case report]. $A r-$ quivos de Neuro-Psiquiatria, 58(2B), 560-565.

Gouveia, P. A. R. (2006). Introdução à reabilitação neuropsicológica de adultos. In J. Abrisqueta-Gomes \& F. H. Santos (Eds.), Reabilitação
Neuropsicológica da teoria à prática (pp. 7382). São Paulo, SP: Artes Médicas.

Gouveia, P. A. R., Prade, C. V., Lacerda, S. S., Boschetti, W. L., \& Andreoli, P. B. (2009). Reabilitação neuropsicológica em fase aguda e crônica após Traumatismo Crânio-Encefálico (TCE) grave: Relato de caso. Contextos Clínicos, 2(1), 18-26.

Heaton, R. K., Chelune, G. J., Talley, J. L., Kay, G. C., \& Curtiss, G. (1993). Wisconsin Card Sorting Test Manual. Revised and Expanded. Odessa, FL: Psychological Assessment Resources.

Hofgren, C., Esbjornsson, E., \& Sunnerhagen, K. S. (2010). Return to work after acquired brain injury: Facilitators and hindrances observed in a sub-acute rehabilitation setting. Work, 36(4), 431-439. doi:10.3233/WOR-2010-1039

Hooson, J. M., Coetzer, R., Stew, G., \& Moore, A. (2013). Patients' experience of return to work rehabilitation following traumatic brain injury: A phenomenological study. Neuropsychological Rehabilitation, 23(1), 19-44. doi:10.1080/09602 011.2012 .713314

Kolb, B. (2004). Mechanisms of Cortical Plasticity after Neuronal Injury. In J. Ponsford (Ed.), Cognitive and Behavioral Rehabilitation: From neurobiology to clinical practice. New York: The Guilford Press.

Lacerda, S. S., Andreoli, P. B., \& Andreoli, S. B. (2008). Reliability of the Brazilian version of Rey auditory and verbal learning test (RAVLTBR). Journal of the International Neuropsychological Society, 14(Suppl. 2), 9-9.

Levine, B., Schweizer, T. A., O’Connor, C., Turner, G., Gillingham, S., Stuss, D. T., ...Robertson, I. H. (2011). Rehabilitation of executive functioning in patients with frontal lobe brain damage with goal management training. Frontiers in Human Neuroscience, 5, 9. doi:10.3389/ fnhum.2011.00009

Loring, D. W. (1999). INS Dictionary of Neuropsychology. New York: Oxford University Press.

Martins, M. R., Bolognani, S. A. P., Pompeia, S., Bueno, O. F. A., \& Miranda, M. C. (2015). Versões Alternativas do Subteste Memória Lógica da WMS-R: Análise de desempenho de uma amostra saudável da cidade de São Paulo. Psicologia: Reflexão e Crítica, 28(3), 444-453. doi:10.1590/1678-7153.201528303 
Osterrieth, P. A. (1944). Filetest de copie d'une figure complex: contribution a létude de la perception et de la memoire. Archives de Psychologie, 30, 286-356.

Reitan, R. M. (1958). Validity of the Trail Making Test as an indicator of organic brain damage. Perceptual and Motor Skills, 8, 271-276.

Rubens, A. B., Geschwind, N., Mahowald, M. W., \& Mastri, A. (1977). Posttraumatic cerebral hemispheric disconnection syndrome. Archives of Neurology, 34(12), 750-755.

Schmidt, M. (1996). Rey auditory and verbal learnig test: A handbook. Los Angeles, CA: WPS.

Schuhfried, G. (2003). RehaCom Version 5. Basic Manual [Software]. Retrieved from http://www. hasomed.de/fileadmin/user upload/RehaCom/ Manuale/ENG/RehaComEN.pdf

Sohlberg, M. M. M. (2009). Reabilitação Cognitiva: Uma Abordagem Neuropsicológica Integrativa. São Paulo, SP: Santos.

Sperry, R. S., Gazzaniga, M. S., \& Bogen, J. E. (1969). Inter-hemispheric relationships: The neocortical commissures; sindromes of hemisferic disconnection. In P. J. Vinken \& Bruyn (Eds.), Handbook of clinical neurology (Vol. 4, pp. 273-290). Amsterdan: North-Holland.

Strauss, E., Sherman, E. M. S., \& Spreen, O. (2006). A compendium of neuropsychological tests: Administration, norms, and commentary $\left(3^{\text {rd }}\right.$ ed.). Oxford, UK: Oxford University Press.

Tosello, D. J. T. (2005). Contribuição para o estudo normativo do Hooper Visual Organization Test (VOT). Psicologia Hospitalar, 13(2), 59-83.

Trexler, L. E. (2000). Empirical support for Neuropsychological Rehabilitation. In A.-L. Chistensen \& B. P. Uzzell (Eds.), International Handbook of Neuropsychological Rehabilitation. New York: Kluwer Academic.
Von Cramon, D., Matthes-von Cramon, D., \& Mai, N. (1991). Problem-solving deficits in brain injured patients: A therapeutic approach. Neuropsychological Rehebilitation, 1, 45-64.

Wall, G., Turner, A., \& Clarke, R. (2013). Evaluation of neuropsychological rehabilitation following severe traumatic brain injury: A case report. Neurocase, 19(6), 530-541. doi:10.1080/13554 794.2012 .701642

Wechsler, D. (1987). Wechsler Memory Scale Revised Edition. Manual. New York: The Psychological Corporation.

Wechsler, D. (2004). Escala de Inteligência Wechsler para Adultos: Manual ( $3^{\text {rd }}$ ed.). São Paulo, SP: Casa do Psicólogo.

Wilson, B. A. (1999). Case Studies in Neuropsychological Rehabilitation. New York: Oxford University Press.

Wilson, B. A. (2008). Neuropsychological rehabilitation. Annual Review of Clinical Psychology, 4, 141-162. doi:10.1146/annurev. clinpsy.4.022007.141212

World Health Organization. (1980). International Classification of Impairments, Disabilities and Handicaps: A Manual of Classification Relating to the Consequences of Disease. Geneva: Author. 